Volume: 2 Issue: 3

Year: 2021

DOI: $10.53811 /$ ijtcmr.987607
International Journal of Traditional and Complementary

Medicine Research
Publisher

Duzce University

\title{
REVIEW
}

\section{Natural Preservatives}

\author{
Busra Kulaksiz Piskin ${ }^{1,2^{*}}$ iD, Gulsun Vildan Seyhan² \\ ${ }^{1}$ İstanbul University, Institue of Health Sciences İstanbul, Turkey, \\ ${ }^{2}$ Biruni University, Faculty of Pharmacy, Department of Pharmacognosy, İstanbul, Turkey, \\ *Corresponding Author: Busra Kulaksiz Piskin, e-mail: bkulaksiz@ biruni.edu.tr
}

Received: 26.08 .2021

Accepted: 05.11.2021

\begin{abstract}
Preservatives are used in cosmetics, pharmaceuticals, food and industrial products to prevent deterioration of the product and to prolong its use. Preservatives are classified into two groups as natural and synthetic according to their source. However, the interest in natural preservatives has increased due to the negative effects of synthetic preservatives on health and the increasing concerns about their safety. Plants have been used in many fields such as medicine, food, perfume and cosmetics since ancient times, and they are important as natural preservatives. There are studies in which the antioxidant, antibacterial and antifungal effects of essential oils, extracts prepared from herbal drugs with various solvents, and herbal active substances purified and isolated from these extracts are investigated and significant results are revealed. For this reason, it is thought that they can be used as preservatives in the cosmetics, pharmaceutical and food industries due to their antimicrobial and antioxidant effects. In this study, plants, drugs, and herbal active substances that are used or can be used as preservatives of herbal origin with regards to their antimicrobial effects were examined.
\end{abstract}

Keywords: Natural Preservatives, Antimicrobial Effects, Cosmetic Products, Food Industry

\section{INTRODUCTION}

Preservatives are substances used in cosmetics, pharmaceuticals, food and industrial products to prevent deterioration of the product and to prolong its use. Deterioration occurs with the effect of light, air, humidity and the effect of microorganisms. Preservatives are generally used with antioxidant, antimicrobial and chelating effects. Preservatives are classified as natural or synthetic based on their source. Due to the negative effects of synthetic preservatives on health, which has been much discussed recently, natural preservatives have started to gain more importance today. Plants are important among natural preservatives. ${ }^{1}$ In this study, plants, drugs and active substances that can be used as natural preservatives, whose antimicrobial effects are the most studied, were examined. Preservatives are substances used in cosmetics, pharmaceuticals, food and industrial products to prevent deterioration of the product and to prolong its use. Deterioration occurs with the effect of light, air, humidity and the effect of microorganisms. Preservatives are generally used with antioxidant, antimicrobial and chelating effects. Preservatives are classified as natural or synthetic based on their source. Due to the negative effects of synthetic preservatives on health, which has been much discussed recently, natural preservatives have started to gain more importance today. Plants are important among natural preservatives. ${ }^{1}$ In this study, plants, drugs and active substances that can be used as natural preservatives, whose antimicrobial effects are the most studied, were examined.

\section{Rubus rosaefolius Smith}

The effectiveness of Rubus rosaefolius leaves as a preservative in gel and emulsion formulations was evaluated. For this purpose, $0.2 \%$ ethanol extract of Rubus rosaefolius leaves was prepared and this extract was used in gel and emulsion formulations for Pseudomonas aeruginosa (ATCC 9027), Burkholderia cepacia (ATCC 25416), Staphylococcus aureus (ATCC 6538), Escherichia coli (ATCC 10536) and Aspergyllus brasiliensis (ATCC 16404) growth in microorganisms was controlled (Tables 1 and 2). As a result of the 
study, it was determined that the ethanol extract did not show any effect against fungi, but showed a significant lethal effect on bacteria. The results meet the criteria of the American Pharmacopoeia, the European Pharmacopoeia, and the Japanese Pharmacopoeia Antimicrobial Efficacy Test ${ }^{2}$
There are different Rubus species (Rubus caesius, Rubus anatolicus, Rubus idaeus) in Turkey. According to the results of the above study, it may be possible to benefit from these species with their protective effects in the food and pharmaceutical industry. ${ }^{2,3}$

Table 1. Results of antimicrobial activity test (CFU/gram) in emulsion formulations using $0.2 \%$ Rubus rosaefolius leaf extract.

\begin{tabular}{lrrrrrr}
\hline Time (Day) & $\mathbf{0}$ & \multicolumn{1}{c}{$\mathbf{2}$} & $\mathbf{7}$ & $\mathbf{1 4}$ & $\mathbf{2 1}$ & $\mathbf{2 8}$ \\
\hline Escherichia coli ATCC 10536 & 6.17 & $<1$ & $<1$ & $<1$ & $<1$ & $<1$ \\
Physiological saline & 6.36 & 6.59 & 5.5 & 5 & 4.71 & 5.78 \\
\hline Pesudomonas aeruginosa ATCC 9027 & 6.07 & $<1$ & $<1$ & $<1$ & $<1$ & $<1$ \\
Physiological saline & 6.27 & 6.28 & 6.53 & 6.15 & 6.59 & 6.64 \\
\hline Burkholderia cepacia ATCC 25416 & 5.62 & $<1$ & $<1$ & $<1$ & $<1$ & $<1$ \\
Physiological saline & 5.59 & 6.11 & 6.48 & 6 & 6.54 & 6.36 \\
\hline Staphylococcus aureus ATCC 66538 & 5.99 & $<1$ & $<1$ & $<1$ & $<1$ & $<1$ \\
Physiological saline & 6.3 & 5.99 & 6.49 & 6.85 & 6.77 & 6.61 \\
\hline Candida albicans ATCC 10231 & 4.72 & 4.64 & 4.43 & 4.87 & 4.92 & 5.04 \\
Physiological saline & 4.72 & 5.41 & 5.41 & 5.62 & 4.72 & 4.53 \\
\hline Aspergillus brasibensis ATCC 16404 & 5.54 & 5.4 & 4.84 & 4.17 & 4.18 & 3.81 \\
Physiological saline & 5.4 & 5.4 & 5.7 & 5.04 & 5.65 & 5 \\
\hline
\end{tabular}

Table 2. Antimicrobial activity test results (CFU/gram) in gel formulations using $0.2 \%$ Rubus rosaefolius leaf extract.

\begin{tabular}{|c|c|c|c|c|c|c|}
\hline Time (Day) & $\mathbf{0}$ & 2 & 7 & 14 & 21 & 28 \\
\hline Escherichia coli ATCC 10536 & 6.18 & $<1$ & $<1$ & $<1$ & $<1$ & $<1$ \\
\hline Physiological saline & 6.36 & 6.59 & 5.5 & 5 & 4.72 & 5.78 \\
\hline Pesudomonas aeruginosa ATCC 9027 & 6 & $<1$ & $<1$ & $<1$ & $<1$ & $<1$ \\
\hline Physiological saline & 6.28 & 6.28 & 6.53 & 6.15 & 6.59 & 6.64 \\
\hline Burkholderia cepacia ATCC 25416 & 5.83 & $<1$ & $<1$ & $<1$ & $<1$ & $<1$ \\
\hline Physiological saline & 5.59 & 6.11 & 6.48 & 6 & 6.54 & 6.36 \\
\hline Physiological saline & 6.3 & 5.99 & 6.49 & 6.85 & 6.77 & 6.61 \\
\hline Candida albicans ATCC 10231 & 4.61 & 4 & 1.84 & 3.81 & Could not be counted & 6.04 \\
\hline Physiological saline & 5.77 & 5.41 & 4.8 & 5.62 & 4.72 & 4.53 \\
\hline Aspergillus brasibensis ATCC 16404 & 5.48 & 5.48 & 4.74 & 4.7 & 4.18 & 4.18 \\
\hline Physiological saline & 5.4 & 5.4 & 5.7 & 5.04 & 5.65 & 5 \\
\hline
\end{tabular}

\section{Lippia origanoides Kunth}

The protective effect of Lippia origanoides leaves in cream, syrup and shampoo formulations has been investigated. In the study, the antimicrobial effect of the essential oil obtained from the leaves of the plant on microorganisms (Aspergillus brasiliensis, Candida albicans, Escherichia coli, Pseudomonas aeruginosa and Staphylococcus aureus) was investigated. In the same study, the protective effect of the essential oil of the plant was evaluated by controlling the microbiological growth in cream, syrup and shampoo formulations in which essential oil was used (Table 3). ${ }^{4}$ The protective efficacy test results of the formulations were evaluated according to the acceptance criteria of the American Pharmacopoeia (USP, 2010).
According to these results, Lippia origanoides essential oil showed fungicidal activity against Candida albicans in the syrup formulation, while it showed fungistatic effect against Aspergillus brasiliensis. The essential oil in the cream formulation was not effective against bacterial strains. The essential oil in shampoo and syrup formulations, on the other hand, is effective against microorganisms and meets the requirements of the American Pharmacopoeia. ${ }^{4}$ The major compounds responsible for the antimicrobial activity of Lippia origanoides essential oil are thymol and carvacrol; minor compounds are also thought to affect the activity synergistically. ${ }^{5}$ Studies with the same plant species show the presence of thymol, 
Volume: 2 Issue: 3

Year: 2021

DOI: $10.53811 /$ ijtcmr.987607
International Journal of Traditional and Complementary

Medicine Research
Publisher

Duzce University carvacrol, thymol/carvacrol, $\alpha$ and $\beta$ phellandrene/p-cimene/limonene and (E)-methyl cinnamate /(E)-nerolidol chemotypes. The chemical content of the plant and the essential oil obtained from the plant should be determined before using it in industrial processes, since the differentiation of chemical content will also cause a change in biological activity. ${ }^{4}$ Lippia canescens and Lippia nodiflora species found in Turkey can also be evaluated in terms of their antimicrobial activities. $^{6,7}$

Table 3. Microbiological growth in cream, syrup and shampoo formulations in which essential oil obtained from Lippia origanoides leaves is added as a preservative.

\begin{tabular}{|c|c|c|c|c|c|}
\hline Formulation & Microorganisms & 0. day & 7. day & 14. day & 28. day \\
\hline \multirow{5}{*}{$\begin{array}{l}\text { Cream + Essential Oil + Polysorbate } \\
80\end{array}$} & Aspergillus brasiliensis & 5.9 & 5.4 & 5.2 & 5.1 \\
\hline & Candida albicans & 5.6 & 5.6 & 5.8 & 5.8 \\
\hline & Escherichia coli & 6.0 & 6.2 & 6.2 & 6.4 \\
\hline & Pseudomonas aeruginosa & 6.2 & 6.0 & 6.4 & 6.6 \\
\hline & Staphylococcus aureus & 6.0 & 5.7 & 6.3 & 6.2 \\
\hline \multirow{5}{*}{ Syrup + Essential Oil + Polysorbate 80} & Aspergillus brasiliensis & 5.0 & 5.4 & 5.3 & 4.5 \\
\hline & Candida albicans & 5.6 & 0 & 0 & 0 \\
\hline & Escherichia coli & 5.0 & 4.0 & 0 & 0 \\
\hline & Pseudomonas aeruginosa & 5.6 & 4.9 & 0 & 0 \\
\hline & Staphylococcus aureus & 5.9 & 4.8 & 4.1 & 0 \\
\hline \multirow{5}{*}{$\begin{array}{l}\text { Shampoo+Essential } \\
80\end{array}$} & Aspergillus brasiliensis & 5.3 & 0 & 0 & 0 \\
\hline & Candida albicans & 5.9 & 0 & 0 & 0 \\
\hline & Escherichia coli & 6.0 & 0 & 0 & 0 \\
\hline & Pseudomonas aeruginosa & 6.0 & 0 & 0 & 0 \\
\hline & Staphylococcus aureus & 6.0 & 0 & 0 & 0 \\
\hline
\end{tabular}

Syzygium aromaticum L., Cinnamomum Schaeff spp.

An outbreak of listeriosis caused by Listeria monocytogenes has been associated with the consumption of pasteurized milk. As a result, pasteurized milk has been evaluated as a medium risk product by the FDA (US Food and Drug Administration). Based on this information, in the study where the antibacterial effect of Syzygium aromaticum buds and essential oils obtained from the leaves and bark of Cinnamomum spp. against Listeria monocytogenes bacteria for 14 days was examined, Cinnamomum spp. essential oil showed strong bactericidal activity. However, it has been noted that higher concentrations of essential oils from Syzygium aromaticum and Cinnamomum species are required to completely inhibit the growth of Listeria monocytogenes. These results show that essential oils obtained from Syzygium aromaticum and Cinnamomum species can be used as natural preservatives in dairy products. ${ }^{8}$ The major compounds responsible for the antimicrobial effect of Syzygium aromaticum essential oil are eugenol, eugenyl acetate and $\beta$-caryophyllene. 9,10 The compounds responsible for the effect of Cinnamomum spp. essential oil are cinnamaldehyde, which is the major compound, and 1-linalool, p-cimen, and eugenol, which are minor compounds. ${ }^{10}$

In a study on cinnamaldehyde, one of the major components of Cinnamomum species, cinnamaldehyde showed an antimicrobial effect against Salmonella and Escherichia coli microorganisms. Salmonella and Escherichia coli are risky microorganisms that reproduce especially in animal foods and water sources. Therefore, it has been noted that cinnamaldehyde could be evaluated to control foodborne pathogens. ${ }^{11}$

Citrus bergamia Risso\&Poiteau, Citrus limon (L.)Burm.f., Citrus sinensis (L.) Osbeck

In a study in which the ethanol extract of bergamot peels was tested against Gram (-) bacteria (Escherichia coli, Pseudomonas putida, Salmonella enterica), and Gram (+) bacteria (Listeria innocua, Bacillus subtilis, Lactococcus lactis ve Saccharomyces cerevisiae), it was noted that bergamot fractions showed antimicrobial effect only against Gram (-) bacteria among the tested microorganisms. ${ }^{12}$ In another study, the inhibitory effect of essential oils obtained from Citrus bergamia, Citrus limon, Citrus sinensis on the growth of Listeria monocytogenes, 
Volume: 2 Issue: 3

Year: 2021

DOI: $10.53811 /$ ijtcmr.987607
International Journal of Traditional and Complementary

Medicine Research
Publisher

Duzce University
Staphylococcus aureus, Bacillus cereus, Escherichia coli and Campylobacter jejuni bacteria was investigated in cabbage leaves and chicken skin. The highest inhibitory effect was observed in Citrus bergamia species. The results of the study were close to the results of another study investigating the inhibitory effects of citral and linalool. $^{13}$

\section{Vaccinium macrocarpon Aiton, Rubus chamaemorus L., Rubus idaeus L., Fragaria ananassa Duch., Vaccinium myrtillus L.}

In a study, were investigated the antimicrobial effects of Vaccinium macrocarpon, Rubus chamaemorus, Rubus idaeus, Fragaria ananassa, Vaccinium myrtillus fruits against microorganisms Helicobacter pylori, Listeria monocytogenes, Salmonella, Staphylococcus aureus, Escherichia coli and Campylobacter spp. and it was found that the fruits inhibited the growth of microorganisms. The effect is thought to be due to phenolic compounds such as phenolic acids, condensed tannins, proanthocyanidins, anthocyanins, flavonoids, and organic acids. ${ }^{10}$

\section{Humulus lupulus L.}

The antibacterial effects of bitter substances such as lupulon and humulon in the resin obtained from Humulus lupulus L. flowers against Streptococcus spp., Escherichia coli, Listeria monocytogenes microorganisms were investigated and it was determined that the hydrophobic parts of these substances inhibit the growth of Gram (+) bacteria as a result of interaction with the cytoplasmic membrane of the bacteria. In the study examining the antimicrobial effect of Humulus lupulus L. essential oil and chloroform extract, antimicrobial activity was observed against Gram (+) bacteria; No antimicrobial activity was observed against Gram (-) bacteria and Candida albicans. ${ }^{10}$

\section{Olea europaea $\mathrm{L}$.}

In order to determine the antimicrobial activity of Olea europaea due to its high phenolic content, many studies have been carried out against various bacteria and fungi in recent years and it is thought that it can be used as an alternative natural preservative. $^{15,16}$ While the antimicrobial effects of crude extracts prepared with different solvents were investigated in the first studies, studies to determine the compounds responsible for the antimicrobial effect have increased in recent years and effective compounds such as oleorepine, ligstroside, tyrosol, hydroxytyrosol and elenoic acid have been identified. ${ }^{10,15}$ Elenoic acid and its derivatives, oleacein and oleocanthal compounds have been proven to have significant antibacterial activity. Although significant antimicrobial activity potentials of Olea europaea L. extracts and effective compounds isolated from the extracts have been demonstrated, more research is needed on their use in the food industry and their application routes. $^{15}$

\section{Some species in the Brassicaceae family}

There are studies reporting that glucosinolate derivative allyl isothiocyanates found in the (Brassica oleracea L.var. capitata, Brassica oleracea L. var. botrytis, Brassica rapa L. subsp. rapa., Brassica nigra L., Brassica oleracea L. var. italica) seeds of species belonging to the Brassicaceae family have an antimicrobial effect. ${ }^{10,17,18}$ According to the results of the study, isothiocyanates showed antimicrobial effect a broad spectrum in nanogram amounts on Gram (+) (Listeria monocytogenes, Staphylococcus aureus) and Gram (-) bacteria (Escherichia coli O157:H7, Pseudomonas corrugata, Salmonella spp.) and yeast (Endomyces fibuliger) and fungi (Aspergillus flavus, Aspergillus niger, Cladosporium cladosporioides, Penicillium citrinum, Penicillium commune) and were showed a broad spectrum antimicrobial effect in nanogram amounts. showed. ${ }^{10}$ The very low amount required to inhibit microorganisms suggests that it can be used as a microbial preservative in the food industry. ${ }^{19}$

\section{Allium spp.}

Allium cepa L. and Allium sativum L. inhibit the growth of Bacillus cereus, Clostridium botulinum type A, Escherichia coli, Lactobacillus plantarum, Salmonella, Shigella spp., Staphylococcus aureus, Aspergillus niger, Candida albicans and many microorganisms and inhibit toxin production. ${ }^{19}$ The antimicrobial effect of allicin is due to the chemical reaction of thiosulfinates with some enzymes containing thiol groups. ${ }^{20}$ It has been determined that allicin has an inhibitory effect against microorganisms in processed meat and meat products. ${ }^{10}$ There is no fresh allicin in the Allium sativum plant. Allicin is formed by the interaction of alliin with the alliin alkyl sulfonate lyase enzyme when the garlic clove is crushed. ${ }^{21}$ A similar phenomenon occurs in onions in the presence of substrate (S-(1-propenyl)-L-cysteine sulfoxide) and thiopropanal-S-oxide, one of the major compounds, is formed. These compounds (allicin and thiopropanal-S-oxide) occurring in garlic and onions are responsible for both antimicrobial effect and flavor and odor. ${ }^{10}$

In another study, flower extracts of Allium 
Volume: 2 Issue: 3

Year: 2021

DOI: $10.53811 /$ ijtcmr.987607
International Journal of Traditional and Complementary

Medicine Research
Publisher

Duzce University scabriscapum Boiss. \&Kotschy, Allium iranicum (Wendelbo)Wendelbo, Allium atroviolaceum Boiss., Allium shelkovnikovii Grossh. species showed antimicrobial activity against pathogenic microorganisms such as Klebsiella pneumoniae, Bacillus subtilis, Bacillus cereus, Staphylococcus aureus and Escherichia coli and it was determined that the effect was caused by the tannin compounds found in the flowers. ${ }^{22}$

\section{Melaleuca alternifolia (Maiden \&Betche) Cheel}

In a study examining the antimicrobial activity of Melaleuca alternifolia essential oil and its major components in oil-based personal care products, MIC values were recorded as $0.4 \%$ for Escherichia coli and Bacillus subtilis and were found to be as effective as parabens in the $0.08 \%-0.8 \%$ concentration range. According to this result, it was determined that it would be appropriate to add tea tree oil as a natural antimicrobial preservative in oil-based formulations. ${ }^{23}$ The essential oil obtained from Melaleuca alternifolia showed significant antimicrobial activity against the microorganisms of Candida albicans, Pseudomonas aeruginosa, Staphylococcus spp. Aspergillus niger. ${ }^{19,24}$ Melaleuca alternifolia essential oil as major components $35-40 \%$ terpinen-4-ol, 4\% 1,8-cineol, 2-5\% p-cymene; it also contains linalool, $\alpha$-terpinene, $\gamma$-terpinene, $\alpha$ terpineol and terpinolene as minor components. ${ }^{19}$ While the compound responsible for the effect against Pseudomonas aeruginosa is p-cymene; the compounds responsible for the action against Candida albicans are terpinen-4-ol and p-cymene compounds. $^{24,25}$

\section{Cupressus sempervirens $\mathbf{L}$.}

According to the results of the study (MIC, MBC, Disk Diffusion Method) in which the antimicrobial activity of Cupressus sempervirens essential oil and methanol extract were evaluated, it was determined that the methanol extract showed strong antibacterial activity against bacteria, while the essential oil showed lower antibacterial activity. However, it was determined that both the essential oil and the methanol extract did not have antifungal activities against Candida albicans. Based on this study, antibiofilm activity against Klebsiella pneumoniae was determined and it was noted to have a strong effect. ${ }^{26} \alpha$-pinene $(48.6 \%)$, $\delta$-3-carene $(22.1 \%)$, limonene $(4.6 \%)$ and $\alpha$ terpineol $(4.5 \%)$ compounds are responsible for the antibacterial activity in the essential oil; phenolic compounds are responsible for the antibacterial activity and the antibacterial activity of the methanol extract. 26, 27 Since Cupressus sempervirens essential oil and methanol extract have strong antimicrobial potential, it is thought that they can be used to increase the shelf life of products industrial and can be evaluated as a natural antimicrobial preservative. ${ }^{26}$

\section{Coriandrum sativum L.}

The fixed oil obtained from the seeds of Coriandrum sativum has significant antimicrobial activity against fungi, some yeasts and Gram (+) and Gram (-) bacteria. This effect is found in the composition of the fixed oil, linalool (57-72\%), terpinen-4-ol (0.1-0.5\%), $\gamma$-terpinene (4.2-9.3\%), p-cymene $(1.12-4 \%)$, limonene (\% 0.3-3.7), $\alpha$ pinene (1.63-4.81\%) and minor $\beta$-pinene, myrcene, camphene, linalyl acetate, sabinene and geranyl acetate compounds. ${ }^{27}$ It has been noted that there are various applications in the food industry in the storage and packaging stages in order to extend the shelf life of the product and to prevent the growth of pathogenic bacteria. ${ }^{28,29}$

\section{Origanum L. spp.}

The major components of the essential oil from Origanum species are thymol and carvacrol; compounds responsible for antimicrobial activity. ${ }^{30}$ The activity is due to interactions of thymol and carvacrol with the biological membrane of bacteria or fungi. ${ }^{31}$ According to the results of the study, when the essential oil is applied to products in the food industry in different concentrations, it can increase the shelf life of the product by preventing or slowing down microbial spoilage. ${ }^{30}$

\section{Thymus vulgaris $\mathrm{L}$.}

The essential oil obtained from Thymus vulgaris showed antibacterial activity against Escherichia coli, Staphylococcus aureus, Staphylococcus epidermidis and Pseudomonas aeruginosa microorganisms. Thymus vulgaris essential oil inhibited microbial growth in cream-gel formulations. ${ }^{32}$

Thymol, carvacrol and caryophyllene oxide as major compounds; terpinen-4-ol, $\gamma$-terpineol, borneol, geraniol. as minor compounds in the composition of essential oil obtained from Tyhmus vulgaris. ${ }^{34}$ While it is possible to use essential oil in the food industry and nutraceutical products; The addition of herbal preservatives to topical formulations in the cosmetic industry can also be a good alternative to synthetic preservatives. ${ }^{33}$ 
Volume: 2 Issue: 3

Year: 2021

DOI: $10.53811 /$ ijtcmr.987607
International Journal of Traditional and Complementary

Medicine Research
Publisher

Duzce University

Table 4. The relationship of different Origanum species and chemical components with their antimicrobial activities is shown.

\begin{tabular}{|c|c|c|}
\hline Origanum spp. & Major Compounds & Microorganism \\
\hline \multirow{6}{*}{ Origanum. vulgare L. } & Carvacrol & Salmonella enteridis \\
\hline & Thymol & Bacillus. cereus, Bacillus. subtilis \\
\hline & Cymene & Escherichia coli \\
\hline & $\alpha$-pinene & Listeria. monocytegenes \\
\hline & Cymenol & Candida albicans \\
\hline & & Pseudomonas aeruginosa \\
\hline \multirow{4}{*}{ Origanum acutidens (Hand.-Mazz.) Letsw. } & p-cymene & Pseudomonas vulgaris \\
\hline & Carvacrol & Staphylococcus aureus \\
\hline & Borneol & Escherichia coli \\
\hline & $B$ - caryophyllene & Klebsiella pneumoniae \\
\hline \multirow{4}{*}{ Origanum compactum Benth. } & Carvacrol & Pseudomonas aeruginosa \\
\hline & Thymol & Staphylococcus aureus \\
\hline & Terpinene & \\
\hline & p-cymene & \\
\hline \multirow{7}{*}{ Origanum. majorana $\mathrm{L}$. } & Terpinene-4-ol & Pseudomonas aeruginosa \\
\hline & Thymol & Staphylococcus aureus \\
\hline & 4-thujanol & Bacillus subtilis, Bacilus cereus \\
\hline & Cis-sabinene hydrate & Escherichia coli \\
\hline & p-cymene & Klebsiella pneumoniae \\
\hline & $\gamma$-terpinene & Candida albicans \\
\hline & & Listeria. monocytegenes \\
\hline
\end{tabular}

\section{Rosmarinus officinalis $\mathbf{L}$.}

In the study in which the antimicrobial activity of the essential oil obtained from the leaves of Rosmarinus officinalis was determined, it was found that the essential oil showed significant antibacterial activity against Klebsiella pneumoniae and Escherichia coli microorganisms. ${ }^{34}$ In another study evaluating the antimicrobial activity of Rosmarinus officinalis ethanol extract on foodborne microorganisms, the MIC values for Gram (+) bacteria were $1 \%$ for Leuconostoc mesenteroide, $0.5 \%$ for Listeria monocytogenes, $0.5 \%$ for Staphylococcus aureus, $0.13 \%$ for Streptococcus mutans and Bacillus cereus. While it was found as $0.06 \%$, no activity was observed on Gram (-) bacteria (Escherichia coli, Salmonella enteritidis and Erwinia carotovora) and yeasts (Rhodotorula glutinis and Cryptococcus laurentii). It has been reported that phenolic diterpenes are responsible for the effect. It is thought that it can be used in the food industry, especially in pasteurized products. ${ }^{35}$ In a study in which ointment formulations containing $2 \%$ and $4 \%$ Rosmarinus officinalis essential oil were applied topically to the wound formed on the skin of rats, the status of the infection caused by Candida albicans and the number of microorganisms on the wound were examined. As a result, it was observed that the number of Candida albicans and infection were much lower in the wounds of the rats in which $4 \%$ essential oil formulation was applied, compared to the wounds of the rats who were treated with $2 \%$ essential oil-containing ointment formulation and without the ointment formulation. This study suggests that an ointment containing rosemary essential oil on Candida albicans infected wounds can accelerate wound healing and can be added as a natural preservative to wound healing formulations. ${ }^{36}$

\section{Quillaja saponaria Molina and Yucca schidigera Roezl}

Saponins show an antimicrobial effect by reducing glucose utilization and enzyme activities of bacteria, suppressing protein synthesis, and interacting with fatty acids and sterols in the bacterial cell wall. ${ }^{37,38}$ Ouillaja saponaria and Yucca schidigera extracts, which are rich in saponins, have been approved by the FDA for use as emulsifiers and flavorings in foods and beverages. Therefore, considering its antimicrobial effects, it can be considered as a natural antimicrobial preservative. ${ }^{38}$

Equisetum arvense $\mathbf{L}$.

When the antimicrobial effects of Equisetum 
Volume: 2 Issue: 3

Year: 2021

DOI: $10.53811 /$ ijtcmr.987607
International Journal of Traditional and Complementary

Medicine Research
Publisher

Duzce University arvense water and ethanol extract against Escherichia coli, Klebsiella pneumonia, Proteus mirabilis, Pseudomonas aeruginosa, Staphylococcus aureus, Staphylococcus saprophyticus and Enterococcus faecalis microorganisms were examined, it was found that both extracts showed inhibitory effects against all microorganisms. ${ }^{39}$

It has been stated that $4 \%$ aqueous extract of Equisetum arvense plant in cream formulations inhibits the growth of Staphylococcus aureus and Escherichia coli microorganisms, therefore the aqueous extract can be used as a preservative in topical formulations. Phenolic compounds are the compounds responsible for the activity in the plant. $^{40}$

In a study investigated the antibacterial and antifungal effects of Equisetum arvense essential oil, diluted 1:10 against Staphylococcus aureus, Escherichia coli, Klebsiella pneumoniae, Pseudomonas aeruginosa, Salmonella enteritidis, Aspergillus niger and Candida albicans microorganisms, a broad-spectrum antibacterial activity was observed. ${ }^{40}$

\section{Argemone mexicana $\mathbf{L}$.}

In a study investigating the antibacterial and antifungal activities of methanol and ethanol extracts of Argemone mexicana plant and cream and ointment formulations prepared from these extracts against Staphylococcus aureus, Pseudomonas aeruginosa, Candida albicans and Aspergillus niger microorganisms, ethanol extract showed stronger antibacterial effects than methanol extract; It was determined that methanol extract showed stronger antifungal effect than ethanol extract. Based on this study, it is thought that Argemone mexicana extracts can be included in cream and ointment formulations as natural preservatives. $^{41}$

\section{Eupatorium glandulosum Michx}

In the study, in which the antimicrobial activity of the gel formulation prepared with the methanol extract of the Eupatorium glandulosum plant for wound healing purposes was evaluated on albino mice, it was found that it had a strong inhibitory effect against Staphylococcus aureus and Escherichia coli bacteria. Thus, it has been stated that it can be evaluated as a natural preservative in the cosmetics and pharmaceutical industries. ${ }^{42}$

\section{CONCLUSION}

In this review, the effects of plants, drugs, active substances, which are used or can be used as preservatives of natural origin today, are revealed with the results of antimicrobial activity against various microorganisms. Its usability in the food industry and cosmetics industry has been evaluated according to the results of the research. Although the degree of usability as a preservative for plants, drugs and plant-derived active substances with antimicrobial activity cannot be determined precisely, MIC values are determined by some researchers. Based on MIC values, a classification was made as strong activity (up to $0.5 \mathrm{mg} / \mathrm{ml}$ ), moderate activity $(0.51-1.0 \mathrm{mg} / \mathrm{ml})$, weak activity (more than $1.1 \mathrm{mg} / \mathrm{ml})^{27}$

When we consider that there are many plant species with antimicrobial effect, there are many plants, drugs and herbal active ingredient options that can be used as preservatives. As a result of the review, it has been revealed that it is possible to use Rubus rosaefolius, Lippia origanoides, Melaleuca alternifolia and Equietum arvense especially in cosmetic preparations; Coriandrum sativum, Szyzgium aromaticum, Cinnamomum spp, cinnamaldehyde, allicin, Cupressus sempervirens as natural preservatives in the food industry. In addition, it has been determined that Origanum spp., Rosmarinus officinalis and Thymus vulgaris are valuable as natural preservatives in both the food industry and cosmetics sectors. In this short review, only studies on plants, herbal extracts or herbal substances which were concluded to be used as a preservative were included not all antimicrobial studies. When we consider the potential of herbs with regards to their antimicrobial activity there is a need for more specific and detailed studies on the use of herbs as preservatives.

\section{REFERENCES}

1. SM Shaikh, RC Doijad, AS Shete, PS Sankpal. A Review on: Preservatives used in Pharmaceuticals and impacts on health. PharmaTutor 2016;4(5):25-34.

2. Ostrosky EA, Marcondes EMC, Nishikawa SO, Lopes PS, Varca GHC, Pinto TJA, Consiglieri TVO, Baby AR, Velasco MVR, Kaneko TM. Rubus rosaefolius extract as a natural preservative candidate in topical formulations. AAPS Pharm Sci Tech 2011;12(2):732-7. 
Volume: 2 Issue: 3

Year: 2021

DOI: $10.53811 /$ ijtcmr.987607
International Journal of Traditional and Complementary

Medicine Research
Publisher

Duzce University

3. Oliveira B, Rodrigues AC, Cardoso BMI, Ramos ALCC, Bertoldi MC, Taylor JG, Cunha LR, Pinto UM. Antioxidant, antimicrobial and antiquorum sensing activities of Rubus rosaefolius phenolic extract. Industrial Crops and Products 2016;84: 59-66.

4. Hernandes C, Pina ES, Taleb-Contini SH, Bertoni BW, Cestari IM, Espanha LG, Varanda EA, Camilo KFB, Martinez EZ, França SC, Pereira AMS. Lippia origanoides essential oil: an efficient and safe alternative to preserve food, cosmetic and pharmaceutical products. J Appl Microbiol 2017;122(4):900-910.

5. Chataing B, Rojas L, Usubillaga A, Mora D. Chemical composition and bioactivity on bacteria and fungi of the essential oil from Lippia origanoides H.B.K. Journal of Essential Oil Bearing Plants 2012;(15)3:454-460.

6. Güner A, Aslan S, Ekim T, Vural M, Babaç M.T. [List of Turkey plants]. 1.Baskı. İstanbul: Nezahat Gökyiğit Botanik Bahçesi ve Flora Araştırmaları Derneği Yayını; 2012.

7. Baytop T. [Treatment with plants in Turkey]. Türkiye'de Bitkiler ile Tedavi. İstanbul, 1984, s. 190.

8. Cava R, Nowak E, Taboada A, Marin-Iniesta F. Antimicrobial Activity of Clove and Cinnamon Essential Oils against Listeria monocytogenes in Pasteurized Milk. J Food Prot 2007;70:2757-63.

9. Alma MH, Ertas M, Nitz S, Kollmannsberger H. Chemical composition and content of essential oil from the bud of cultivated Turkish clove (Syzygium aromaticum L.). Bio Res 2007;2 (2): 265-269.

10. Davidson PM, Bozkurt Cekmer H, Monu EA, Techathuvanan C. The use of natural antimicrobials in food: An overview. Handbook of Natural Antimicrobials for Food Safety and Quality, Wood head Publishing/Elsevier, Cambridge, UK. 2014.p. 6-10.

11. Yossa N, Patel J, Macarisin D, Millner P, Murphy C, Bauchan G, Lo MY. Antibacterial activity of cinnamaldehyde and sporan against Escherichia coli O157:H7 and Salmonella. J Food Process Preserv 2012;1:1-11.

12. Mandalari G, Bennett R.N, Bisignano G, Trombetta D, Saija A, Faulds CB, Gasson MJ, Narbad A. Antimicrobial Activity of Flavonoids Extracted from Bergamot (Citrus bergamia Risso) Peel. A By product of the Essential Oil Industry. Journal of Applied Microbiology 2007;103:2056-2064.

13. Fisher K, Phillips CA. The effect of lemon, orange and bergamot essential oils and their components on the survival of Campylobacter jejuni, Escherichia coli O157, Listeria monocytogenes, Bacillus cereus and Staphylococcus aureus in vitro and in food systems. J Appl Microbiol 2006;101(6):1232-40.

14. Zanoli P, Zavatti M. Pharmacognostic and pharmacological profile of Humulus lupulus L. J Ethnopharmacol 2008;116:383-96.

15. Thielmann J, Kohnen S, Hauser C. Antimicrobial activity of Olea europaea Linné extracts and their applicability as natural food preservative agents. International Journal of Food Microbiology 2017;251;48-66.

16. Medina E, Garcia A, Romero C, Castro AD, Brenes M. Study of the anti-lactic acid bacteria compounds in table olives. International Journal of Food Science and Technology 2009;44:(7)1286-1291.

17. Delaquis PJ, Mazza G. Antimicrobial properties of isothiocyanates in food preservation. Food Technology 1995;49: 73-84.

18. Dufour V, Stahl M, Baysse C. The antibacterial properties of isothiocyanates. Microbiology 2015;161(2):229-43.

19. Sofos JN, Beuchat LR, Davidson PM, Johnson EA. Naturally occurring antimicrobials in food. Regul Toxicol Pharmacol 1998;28(2):71-2.

20. Ankri S, Mirelman D. Antimicrobial properties of allicin from garlic. Microbes and Infection. 1999;2;125-129.

21. Marchese A. Antifungal and antibacterial activities of allicin: A review. Trends in Food Science \& Technology 2016;52:49-56.

22. Vukics V, Kery A, Guttman A. Flower extracts and their essential oils as potential antimicrobial agents for food uses and pharmaceutical applications. Comprehensive Reviews in Food Science and Food Safety 2008;11(1):34-55.

23. Mantil E, Daly G, Avis TJ. Effect of tea tree (Melaleuca alternifolia) oil as a natural antimicrobial agent in lipophilic formulations. Can J Microbiol 2015;61(1):82-8.

24. Dweck AC. Natural preservatives. Research Director, Peter Black Medicare Ltd., White Horse Business Park, Aintree Avenue, Trowbridge, Wiltshire, UK. BA14 0XB.

25. Manufacturing Chemist, March 1993. Essential evaluation: taking a closer look at natural oils. Anon.

26. Selim SA, Adam ME, Hassan SM, Albalawi AR. Chemical composition, antimicrobial and antibiofilm activity of the essential oil and methanol extract of the Mediterranean cypress (Cupressus sempervirens L.) BMC complementary and alternative medicine 2014;14(1):179.

27. Silva F, Domingues CF. Antimicrobial activity of coriander oil and its effectiveness as food preservative. Critical Reviews in Food Science and Nutrition 2017;57:1:35-47.

28. Rodriguez-Lafuente A, Nerin C. Batlle R. Active paraffin based paper packaging for extending the shelf life of cherry tomatoes. J. Agric. Food Chem 2010;58:6780-6786.

29. Rodriguez A, Batlle R. and Nerin C. The use of natural essential oils as antimicrobial solutions in paper packaging. Part II. Prog. Org. Coat 2007;60:33-38. 
Volume: 2 Issue: 3 Year: 2021

DOI: $10.53811 /$ ijtcmr.987607
International Journal of Traditional and Complementary

Medicine Research
Publisher

Duzce University

30. Rodriguez-Garcia I, Silva-Espinoza BA, Ortega-Ramirez L, Leyva JM, Siddiqui MW, Cruz-Valenzuela MR, Gonzalez-Aguilar GA, Ayala-Zavala JF. Oregano essential oil as an antimicrobial and antioxidant additive in food products. Crit. Rev. Food Sci. Nutr 2016;56(10):1717-27.

31. Cristani M, D’Arrigo M, Mandalari G, Castelli F, Sarpietro MG, Micieli D, Venuti V, Bisignano G, Saija A, Trombetta D. Interaction of four monoterpenes contained in essential oils with model membranes: implications for their antibacterial activity. J Agric Food Chem 2007;55(15):6300-8.

32. Silva Gonçalves GM, Srebernich SM, Bragagnolo N, Madalozzo ES, Merhi VL, Pires DC. Study of the composition of Thymus vulgaris essential oil, developing of topic formulations and evaluation of antimicrobial efficacy. Journal of Medicinal Plants Research 2016;7(23):1736-1745.

33. Mancini E, Senatore F, Monte DD, Martino LD, Grulova D, Scognamiglio M, Snoussi M, Feo VD. Studies on Chemical Composition, Antimicrobial and Antioxidant Activities of Five Thymus vulgaris L. Essential Oils. Molecules 2015;20:12016-12028.

34. Martac IM, Podea P, Determination of antimicrobial and antioxidant activities of essential oil isolated from Rosmarinus officinalis L. Carpathian Journal of Food Science and Technology 2012;4(2):40-45.

35. Del Campo J, Amiot MJ, Nguyen-The C. Antimicrobial effect of rosemary extracts. J Food Prot 2000;63(10):1359-68.

36. Nejati H, Farahpour MR, Nagadehi MN. Topical Rosemary officinalis essential oil improves wound healing against disseminated Candida albicans infection in rat model. Comparative Clinical Pathology 2015;24(6):1377-1383.

37. Yu ZH, Ding XZ, Xia LQ, Xiao XQ, Cao ZP, Xu S, Liu XM. Antimicrobial Activity and Mechanism of Total Saponins from Allium chinense. J Food Science 2013;34(15):75-80.

38. Vijay KJ, Dwivedi HP, Yan X. Novel Natural Food Antimicrobials Annual Review of Food Science and Technology 2012;3:381-403.

39. Al-Snafi EA. Antimicrobial effects of medicinal plants (Part 3): plant based review. IOSR Journal Of Pharmacy 2016;6(10):67-92.

40. Singh S, Sarkar BK, Grace XF, Devgan M. Antimicrobial evaluation of herbal formulation of Equisetum arvense. European Journal of Biomedical and Pharmaceutical Sciences 2015;2(3):908-912.

41. Alzomor AK, Moharram AS, Noman NM, Alafifi J, Mokred H, Alaregi N. Extraction, formulation and evaluation of Argemone mexicana Linn leaves as antimikrobiyal cream and ointment. International Journal of Pharmaceutical Research and Bio-science 2016;5(4):37-51.

42. Raju PK, Srinivas P, Sadanandam M. Oral and topical preparations using natural products. Journal of Natural Pharmaceuticals 2013;4(1):37-46. 